\title{
SIMULATION-BASED SUSTAINABLE MANUFACTURING SYSTEM DESIGN
}

\author{
Juhani Heilala \\ Saija Vatanen \\ Hannele Tonteri \\ Jari Montonen \\ Metallimiehenkuja 6, Espoo \\ P.O. Box 1000 \\ VTT Technical Research Centre of Fin- \\ land \\ 02044 VTT, FINLAND \\ Salla Lind \\ Tekniikankatu 1 \\ P.O. Box 13000 \\ VTT Technical Research Centre of Fin- \\ land \\ 33101 Tampere, FINLAND
}

\author{
Björn Johansson \\ Johan Stahre
}

\begin{abstract}
Manufacturing simulation and digital engineering tools and procedures have had a positive impact on the manufacturing industry. However, to design a sustainable manufacturing system, a multitude of system dimensions must be jointly optimized. This paper proposes an integrated simulation tool helping to maximize production efficiency and balance environmental constraints already in the system design phase. Lean manufacturing, identification and elimination of waste and production losses, and environmental considerations are all needed during development of a sustainable manufacturing system. Engineers designing the manufacturing system need decision support, otherwise sub-optimization is more likely to occur. We present methods for calculating energy efficiency, $\mathrm{CO} 2$ emissions and other environmental impacts integrated into factory simulation software.
\end{abstract}

\section{INTRODUCTION}

Sustainable manufacturing system design means taking into account both economic and ecological constraints. Sustainable business models and environmental accounting are growing business concerns. However, there are multiple approaches to measuring the total environmental footprint of an organization or supply chain, and as of today there is no agreed-upon single standard. The environmental and climate impacts of energy use are rapidly becoming a major issue facing industry and society. Carbon dioxide ( $\mathrm{CO} 2)$, a major greenhouse gas, is emitted into the atmosphere directly when fuels are combusted on-site, and indirectly when electricity is consumed (particularly when fossil fuels are used to generate the electricity). The rising cost of energy is also a factor that must be understood during the manufacturing design phase. More energy-efficient solutions can create huge savings during the lifetime of equipment.

This paper reviews some suitable approaches for environmental impact analysis during system development, shows a link between lean manufacturing and environmental impacts, and presents some mid-term results of the SIMTER project. The main goal is to use Discrete Event Simulation (DES) also as a tool for environmental impact analysis.

\section{MANUFACTURING SYSTEM DESIGN}

A manufacturing system is made up of entities (input and outputs), activities, resources and controls (Harrel and Tumay 1995). It encompasses processes but also includes the resources and controls for carrying them out, as shown in Figure 1.

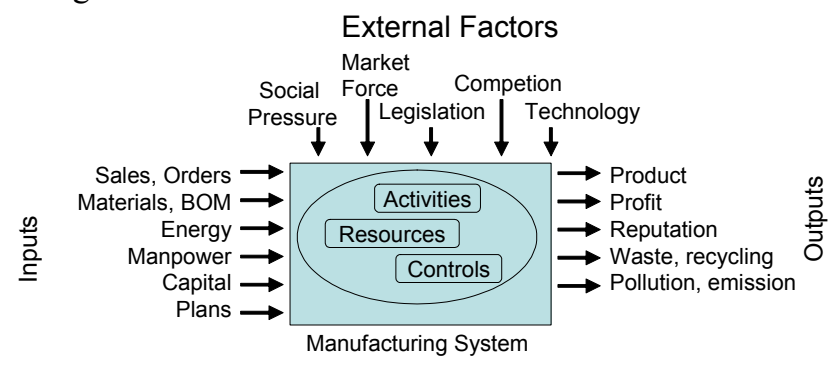

Figure 1: A manufacturing system

Manufacturing system design involves a number of interrelated subjects including tooling strategy, materialhandling systems, system size, process flow configuration, flexibility needed for future engineering changes or capacity adjustment, and space strategy. Production process design is a critical area, since any decision will affect the system behavior for a long time to come, and/or be very costly to change once the system is up and running. Material han- 
dling is another area that deserves intensive study. Although this function does not add value directly to the product, it facilitates the production process flow. System design emphasizes details: how, where and when the process is to be performed. It selects the right equipment and resources to fulfill the process flow.

Production engineering and management decisions involve the consideration of many interdependent factors and variables as shown here. There are far too many of them for the human mind to cope with at once, in which case simulation modeling could help.

Discrete event/material flow/factory simulation is used in the design phase to evaluate concepts and optimize system solutions before investment decisions are made. The common aim is to identify problem areas, and quantify or optimize production system performance such as throughput under average and peak loads, utilization of resources, labor and machine, staffing requirements, work shifts, bottlenecks, choke points, queuing at work locations, queuing caused by material handling devices and systems, effectiveness of the scheduling system, routing of material, work in process, and storage needs.

\subsection{Lean Manufacturing}

Waste elimination is one of the most effective ways to increase the profitability of any business. Processes either add value or waste during the production of a goods or service. Waste (Japanese muda) and its elimination form the core of the Toyota Production System (Monden 1993), also known as lean manufacturing. Lean typically targets the seven so-called deadly wastes, which are:

1. Overproduction

2. Unnecessary inventory

3. Excess motion

4. Waiting

5. Transportation

6. Over-processing, inappropriate processing

7. Non-right the first time, defects

To eliminate waste, it is important to understand exactly what waste is and where it occurs. While products differ significantly between factories, the typical wastes found in manufacturing environments are quite similar. For each kind of waste, there is a strategy to reduce or eliminate its effect on a company, thereby improving overall performance and quality.

When machines are optimally tuned to accomplish the desired work, increased operating efficiency reduces energy waste. TPM (Total Preventative Maintenance), similarly to OEE (Overall Equipment Efficiency) methodology, identifies the losses that lower equipment efficiency, e.g. waiting, set-ups, and reduced speed. Emphasis on equipment efficiency can lead to reduced costs, increased productivity, and fewer defects. Eradicating waste and losses in the design phases maximizes the productivity of equipment throughout its lifetime.

DES is one tool for identification of production waste (e.g. waiting, work in process, inventories, transportation). Value Stream Mapping (VSM) and other process modeling methods are also used in lean manufacturing system development and analysis.

Development of a sustainable manufacturing system adds more parameters to be handled simultaneously. This is a problem if the decision-makers need to handle a multitude of different parameters that are not incorporated into the analysis of one single simulation. Normally, simulation tries to represent reality, only paying heed to the specific parameters evaluated in that specific analysis; thus in most cases factory simulation is not used for environmental impact analysis. It leads to sub-optimization, where only a few of the many parameters are included in the simulation.

\section{SUSTAINABLE MANUFACTURING}

Sustainable manufacturing must be eco-efficient, and one method used is Life Cycle Assessment (LCA). LCA is a method for evaluating environmental impacts associated with a product during its lifetime (EN-ISO 140402006 , EN-ISO 14044 2006.) The assessment can be accomplished by identifying and quantitatively describing the product requirements for energy and materials, and the emissions and waste released into the environment. The product under study is examined from the initial extraction and processing of raw materials through manufacturing, distribution and use to final disposal, including the transport involved, i.e. its whole life cycle (see Figure 2.)

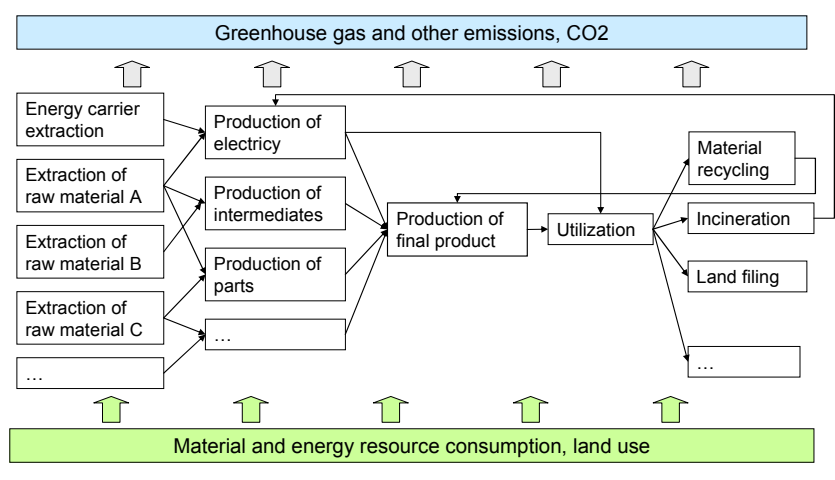

Figure 2: Product life cycle, based on EU LCA platform

Typically, industrial modeling with LCA describes static models compared to DES. Examples of publications from different industrial areas are pharmaceutical intermediates (Jödicke et al. 1999), a nitric acid plant (Alexander et al. 2000), boron production (Azapagic and Clift 1999), phenolic-resin manufacturing (Kheawhom and Hirao 2004), and cement production (Gäbel and Tillman 2005).

There are some examples of the use of DES: Solding and Thollander (2006) and Solding and Petku (2005) used 
discrete event simulation to find energy bottlenecks in foundries. Persson and Karlsson (2007), Alvemark and Persson (2007), and Ingvarsson and Johansson (2006) used discrete event simulation as a tool for environmental measurements in food production. A combination of LCA and DES was employed. Five LCA parameters were incorporated in the DES models: $\mathrm{CO} 2$ eq., NOX eq., $\mathrm{SO} 2$ eq., ethene eq., and energy eq. The results show that it is possible to jointly evaluate economic and environmental impacts.

\subsection{Environmental Waste}

According to the U.S. Environmental Protection Agency (EPA, <http://www.epa.gov>), environmental waste is an unnecessary use of resources or a substance released into the air, water, or land that could harm human health or the environment. Environmental wastes can occur when companies use resources to provide products or services to customers, and/or when customers use and dispose of products. Environmental wastes include 1) energy, water, or raw materials consumed in excess of what is needed to meet customer needs; 2) pollutants and material wastes released into the environment, such as air emissions, wastewater discharges, hazardous wastes and solid wastes (trash or discarded scrap); 3) hazardous substances that adversely affect human health or the environment during their use in production or their presence in products (EPA 2007a).

Environmental and energy wastes are not explicitly listed in the seven deadly wastes of lean manufacturing, but they are embedded in it and related. Like other lean wastes, environmental wastes do not add customer value. They also represent costs to the enterprise and society in general. Using environmental metrics in lean efforts will allow design engineers and production managers to document the environmental benefits that are part of lean implementation. EPA has assembled a list of environmental metrics that may be of use to organizations implementing lean manufacturing. EPA has also published training material on the Lean and Environment Toolkit (EPA 2007a) and the Lean and Energy Toolkit (EPA 2007b)

\subsection{GreenSCOR Environmental Metrics}

A more recent approach is GreenSCOR, (2008). The SCOR (Supply Chain Operations Reference) model is a proven framework for dealing with supply chain scope and process operations and measuring supply chain performance. SCOR also provides a foundation for environmental accounting in the supply chain. The Supply Chain Council <http: //www. supply-chain.org > is proposing a set of strategic environmental metrics that can be added to the SCOR model to effectively allow it to be used as a framework for environmental accounting. The proposed metrics are:

1. Carbon Emissions, tons $\mathrm{CO} 2$ Equivalent

2. Air Pollutant Emissions, tons or $\mathrm{kg}$

3. Liquid Waste Generate, tons or $\mathrm{kg}$

4. Solid Waste Generate, tons or kg

5. \% Recycled Waste, percent

These metrics can be applied in the fabrication phase, at the factory level or even in a single manufacturing phase.

\subsection{Environmental Metrics}

The measures must include priority chemicals that are of particular concern because of their toxicity, persistence in the environment, and/or their potential to bioaccumulate in organisms at higher levels in the food chain. The usage of these chemical and toxic materials should be identified during the production system design.

Companies and other non-governmental organizations have also developed guidance on environmental metrics. The Global Reporting Initiative provides guidance for company-wide environmental and sustainability metrics see <http: //www.globalreporting.org >. The Facility Reporting Initiative provides guidance for facilitywide environmental and sustainability metrics - see <http://www.facilityreporting.org $>$. The Greenhouse Gas Protocol Initiative provides a tool for calculation - see <http: / / www. ghgprotocol. org/>.

While these resources do not focus explicitly on process level environmental metrics, most of the metrics in these frameworks can be considered and applied at process or sub-process levels.

\subsection{EU LCA Platform and other public sources of inventory data}

One of the challenges of environmental impact calculation is the data needed. Public sources of information include e.g. the European Commission's information hub on life cycle thinking-based data, tools and services. <http://lca.jrc.ec.europa.eu/>

Other public sources of inventory data are as follows: In 1996 the International Iron and Steel Institute (IISI) launched its worldwide life cycle inventory (LCI) study for steel products. The study was updated in 2000 and a second update is due in 2008 (see <http://www.worldsteel.org $>$ ). An environmental profile report for the European Aluminium Industry is available on the website of the European Aluminium Association (see <http://www.aluminium.org $>$ ). The following link provides eco-profiling and LCA within PlasticsEurope:

<http://www.lca.plasticseurope.org>. 
Getting detailed data for manufacturing processes like turning, milling or welding is the real challenge, since the parameters depend also on the product.

\section{THE SIMTER APPROACH}

The SIMTER project is one of the efforts being made to introduce joint analysis of 1) environmental impact calculations in combination with discrete event simulation and 2) a virtual analysis tool for level-of-automation evaluations in combination with ergonomic considerations. The aim of the cross-disciplinary SIMTER project is to improve optimization by introducing more parameters enabling joint analysis of multiple synergistic phenomena. The SIMTER tool will be an interactive computer-based system intended to help decision-makers use data and models to identify and solve problems and to make decisions regarding human and environmentally-friendly, sustainable manufacturing systems. The tool under development is a decision support for manufacturing system design engineers, targeted for SME. The SIMTER project has also been presented elsewhere (Lind et al. 2008).

\subsection{SIMTER tool}

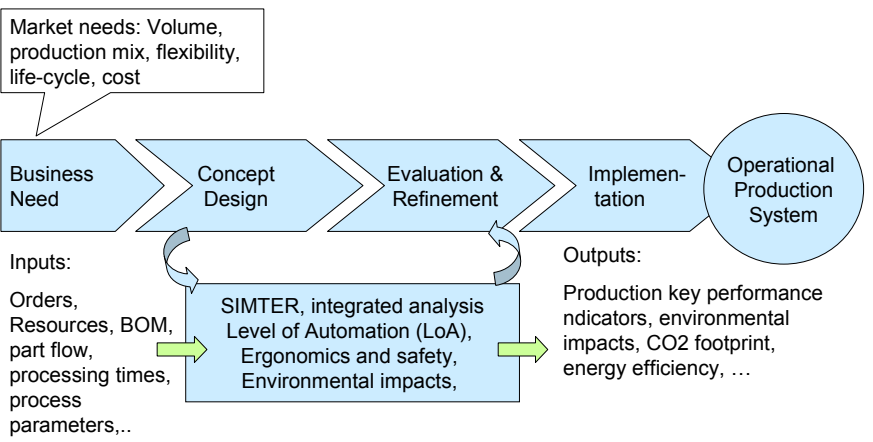

Figure 3: The SIMTER tool covers the system planning phase

The SIMTER tool covers the manufacturing system planning phase (see Figure 3). At the upper level is a discrete event simulation tool analyzing production flow, efficiency and other key performance issues. At the lower, workstation level the focus is on the task, workplace, or process step. Level of Automation (LoA) and ergonomics analysis are also carried out at this level. The lowest level is the product, since material data and part dimensions are needed for analysis.

The SIMTER framework supports hierarchical analysis. This hierarchical approach of the SIMTER subtools is one of the key issues in integrating e.g. environmental and ergonomics subtools (Figure 4). The shared interests are e.g. energy, materials, wastes, exposures, additional/eliminated work tasks and, for productivity, the cycle times. However, the specific details of shared interest may vary depending on the point of view. For example, from an environmental perspective the material or process may have excellent characteristics, but from an ergonomic standpoint it may be harmful. Precluding the conflict may require a special solution that needs checking also from the LoA point of view in order to reach an outcome that is acceptable overall. The shared interests and their databases as a common shared database between all the subtools are significant features that will provide a faster design and development process with better solutions.

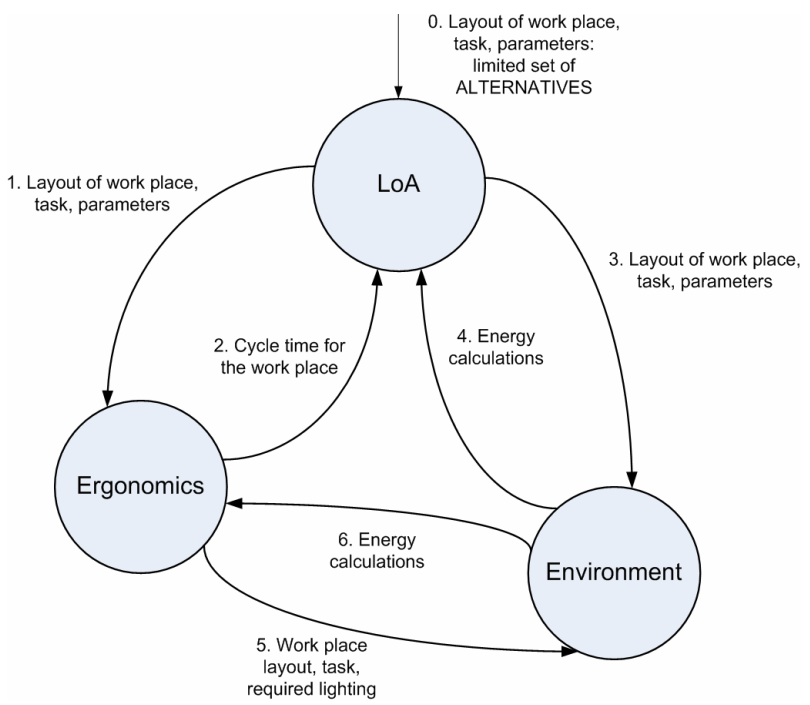

Figure 4: SIMTER tool: Information flow and shared data within the tool (Lind et al. 2008)

\subsection{Development Platform}

In order to avoid using several pieces of simulation software and to reduce the total cost of the SIMTER tool, it has been decided to exploit commercial software that includes both factory and robotic simulation features on a single platform - 3DCreate and 3DRealize of Visual Components $<$ http: / / WWW. visualcomponents. com $>$. If pre-engineered re-usable sub-model elements are available, model building is a rapid process. (See Figure 5). 3D features are needed in ergonomic analysis with a digital human model or robotic work-cell design.

The selected system is extendable and supports add-on application development. Two examples reported earlier are: 1) the OSKU digital man model (Helin et al. 2007) which, in fact, is expected to be developed further in the SIMTER project, and 2) Total Cost of Ownership (TCO) (Heilala et al. 2006 and 2007) analysis methodology integration. It is possible to integrate the external application into the simulation, and to read and write data from/to spreadsheets or other external files. During the SIMTER project it is planned to implement the plug-ins on the 
3DCreate platform for each of the three SIMTER subareas: LoA, ergonomics and environmental impacts.

\begin{tabular}{|l|l|l|}
\hline Geometry: & \\
Materials & & \\
Parameter control \\
Hierachical tree model \\
Lightweight
\end{tabular}

Digital Component properties
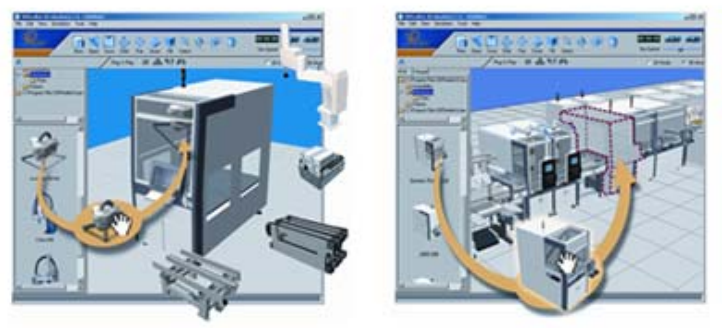

Figure 5: Component based simulation

\section{SIMTER ENVIRONMENTAL SUBTOOL}

The authors are proposing to use also environmental impact analysis integrated into DES modeling. The proposed integration is a hybrid method, a combination of DES and analytic calculation (Figure 6). Traditional factory simulation, DES run results are used for analytical calculation of environmental metrics.

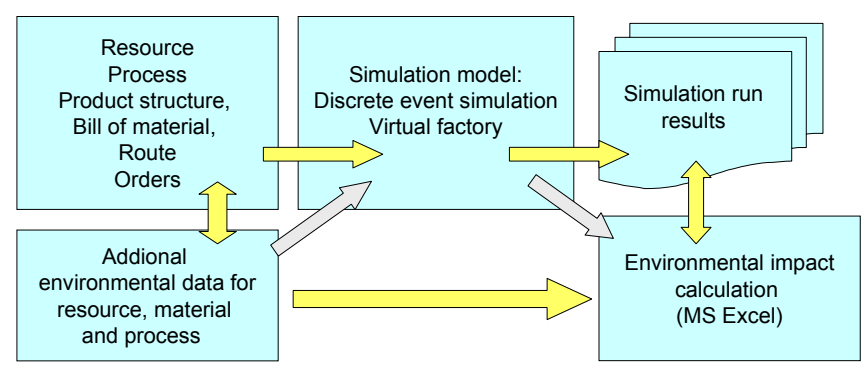

Figure 6: Simplified analysis flow

To be able to consider the environmental impacts of a process, it is important that the environmental parameters are assessed simultaneously in the same simulation model along with the process parameters. Thus, the environmental considerations can be made at the time of production system planning. However, so far no unified method for this approach has been found. In this domain, the intent of the SIMTER project is to enable Life Cycle Assessment on a detailed level, where cause and effect can be measured over time with the dynamics of discrete event simulation influencing each product's way through the production system ("gate to gate"). The SIMTER tool is planned to include Life Cycle Inventory Analysis (LCI) concentrating on the most important environmental aspects of production systems.

Discrete event simulation needs resource, bill of material and product route data, process, order, production schedule, volume, mix, and data for system availability, set-ups, planned maintenance, reliability, machine breaks and production quality rate data. As output we get equipment operation data; percentages of machine states (on, off, standby, under repair), thus getting the basis for energy need calculations. From capacity data we are able to calculate factors depending on piece count and material used during operations.

The first development steps use environmental product and process data indirectly, as shown in Figure 6. Based on various partially commercial databases, both material related data and manufacturing process data are available. The data is entered by the user into the SIMTER input database. In the analysis phase, the environmental data and simulation run results are combined in an MS Excel workbook. Later, the potential for more direct and automated access to these databases will be evaluated.

\subsection{SIMTER Environmental Metrics}

The environmental metrics are adapted from EPA and GreenSCOR. In the first development phase the following metrics are tested:

- Energy consumption, direct and indirect

- $\mathrm{CO} 2$ emissions, direct and indirect

- Other air emissions NOx, VOC, ..

- Solid waste, hazardous waste

- Water emissions

Environmental calculations are based on the number of products manufactured, raw materials used, machine utilizations, scrap and rework rate. The results of production simulation runs used in analysis are based on either the time-unit (i.e. machine operation time), number of working cycles done, or number of manufactured units.

For example, electricity usage, cost of energy and also indirect $\mathrm{CO} 2$ emissions from a machine are based on equipment operating data. If there are any process phases or equipment that use fuels, the direct $\mathrm{CO} 2$ is also calculated.

\subsection{LCI Data}

Part of the development is to get environmental inventory data as easily as possible and preferably using public 
databases. One example is shown in Figure 7. In the development phase, various methods for data browsing are tested.

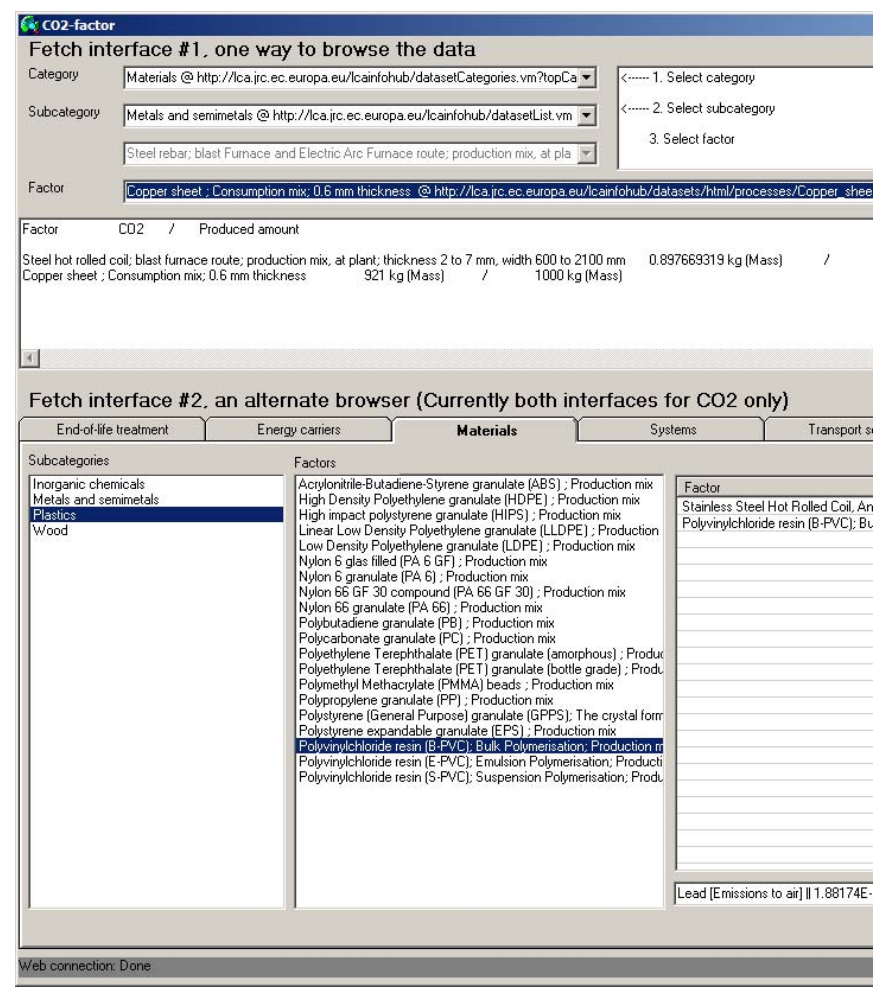

Figure 7: Getting data from the EU's LCA platform

\subsection{Energy Efficiency Analysis}

The SIMTER technique estimates energy use based on information provided by equipment manufacturers. It calculates energy use for specific equipment or process activities using equipment energy specifications (often obtained from equipment manuals or vendors) coupled with equipment operation data (e.g. number of hours the equipment is in different modes of operation). While such calculations are not very precise, they can indicate the order of magnitude of energy use. This type of analysis can look not only at where and how much energy is used, but also opportunities to reduce energy costs through load shifting (shifting electricity use to off-peak times), changing the mix of energy sources, and other strategies as well.

Peak rate energy is more expensive. One of the primary data sources for energy cost data is the facility's utility bill (EPA 2007b). Utility bills often include the following types of data: 1) Consumption charges; electricity is charged based, in part, on the amount of electricity used (in kilowatt-hours, kWh) over a billing period. The per kilowatt-hour rate for electricity may vary based on the time of year (e.g. winter or summer season) and/or the time of day (peak or off-peak hours). 2) Demand charges; for many industrial electricity customers, there will be a demand charge (per kilowatt) in the bill that is based on the peak electricity use each month averaged over a short time period (e.g. 15 minutes). The facility may pay more for demand costs than consumption costs, although the two costs may be a single line item in the utility bill. Thus we need to show and calculate peak demands of energy. By lowering or shifting peak demand, the cost can be reduced.

Potential energy saving could be $20-27 \%$ or even more (EPA 2007b, Westerkamp 2008). The energy is also the biggest factor in terms of $\mathrm{CO} 2$ emissions at the discrete manufacturing factory level. Longer supply chain also increases emissions during transportation.

\section{ILLUSTRATIVE CASE EXAMPLE}

The following illustrative case simulation model was built using existing simulation model library components. The SIMTER “Toy Case" has 5 processing steps, assembly (automated and manual workstation), inspection, painting, drying and packing, as shown in Figures 8 and 9.

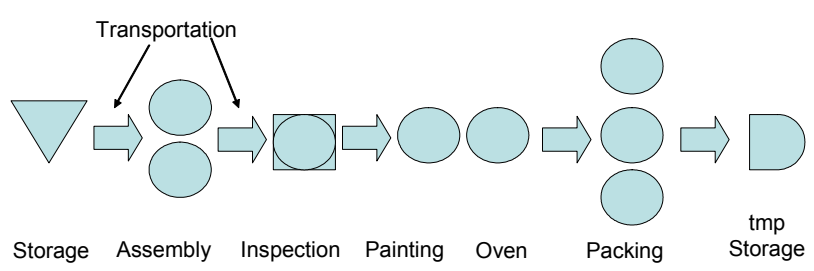

Figure 8: Process flow of case example

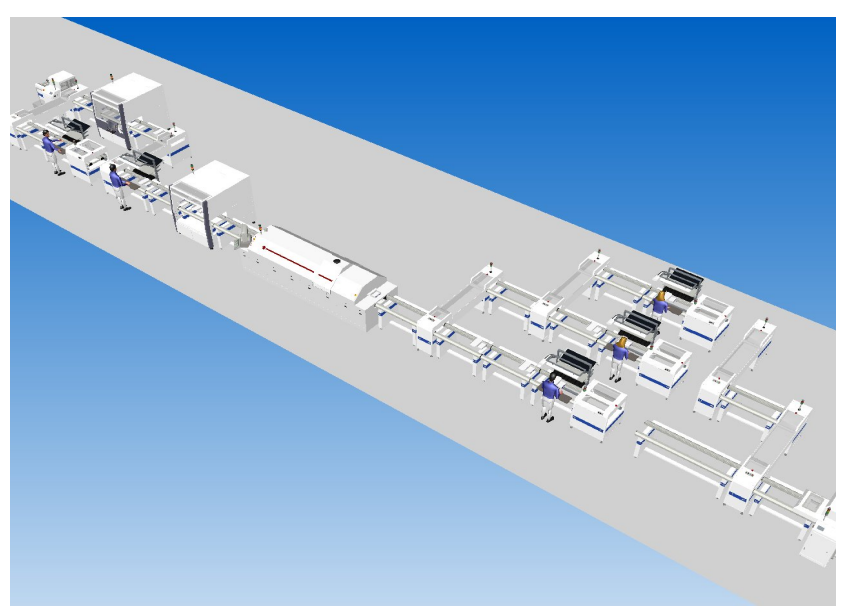

Figure 9: Simulation model

The product consists of four parts, made from electronics plastics, wood and iron. The simulation model shown in Figure 9 might be infeasible in real life, but is a good case for testing the method.

At the current development state, environmental impact is calculated in an MS Excel workbook as shown in Figures 10 and 11. The simulation model can read and write data from/onto an Excel sheet. 


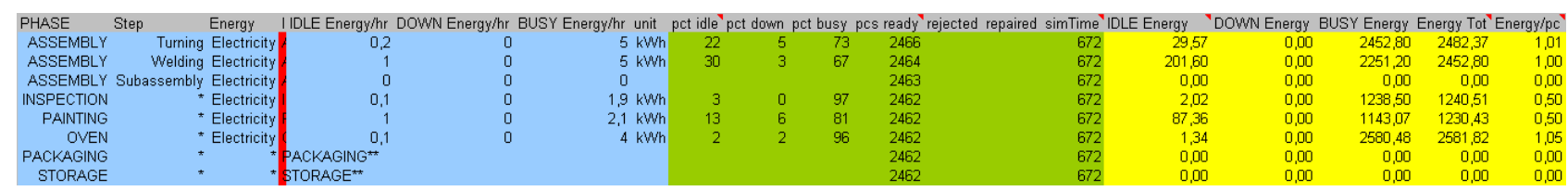

Figure 10: Resource sheet: Equipment energy data, simulation run results and energy calculations

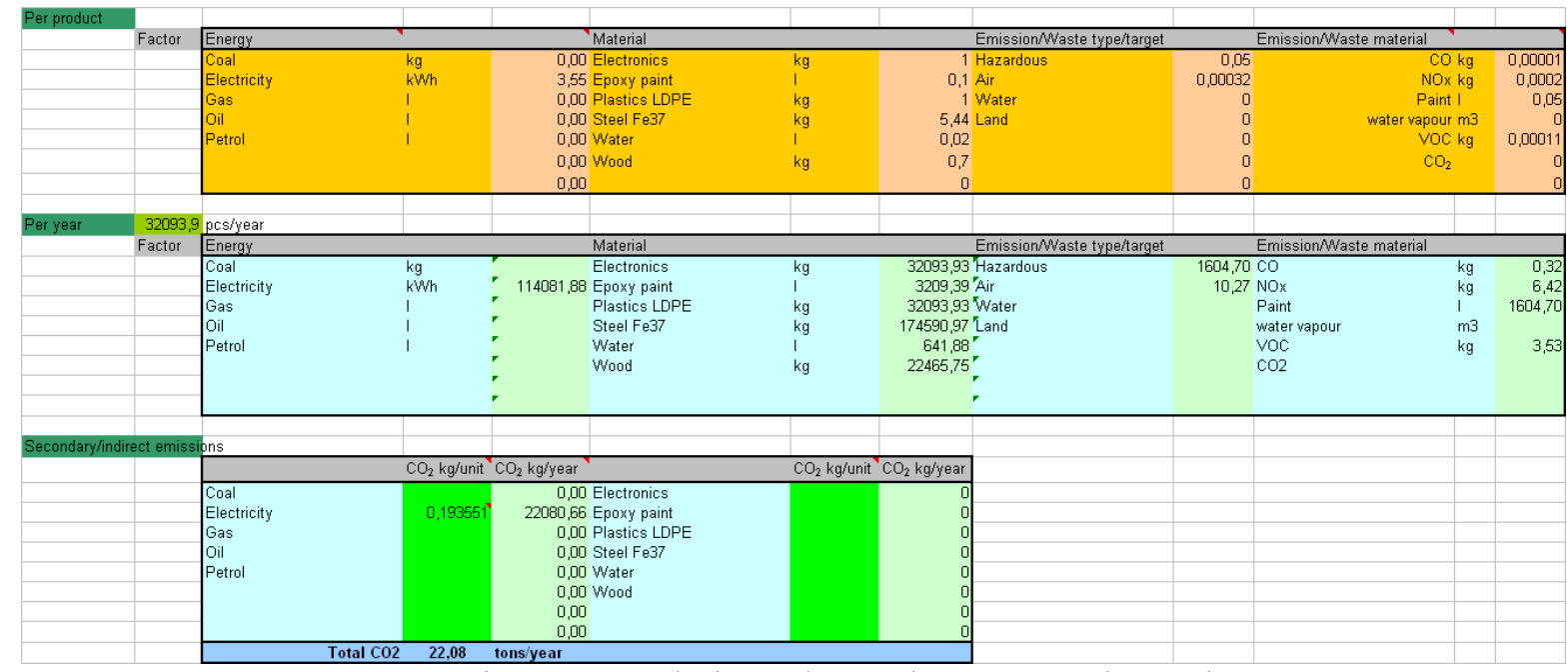

Figure 11: Analysis results are shown per product and per year

The simulation model calculates the percentage of machine states, idle, down, busy, repair, in simulated time. Similarly, energy needs in different states are known and the total energy need is calculated. In this case the simulation run was 672 hours, or 4 weeks. The results are shown per product and per year. The direct and indirect environmental impacts are also calculated.

\section{DISCUSSION AND CONCLUSIONS}

The authors are in the process of creating an integrated manufacturing simulation tool. A feasibility and state-ofthe-art review has been presented elsewhere (Lind et al. 2008). Environmental responsibility has grown steadily as a corporate concern for the past decade. Increasing laws and regulations, coupled with the recognition that developing more eco-friendly manufacturing operations is "the right thing to do," have put sustainability at or near the top of most companies' agenda. The rising cost of energy and climate change are also setting priorities for development. In the design of a new manufacturing system, engineers have normally focused on system productivity, capacity, and other key performance indicators of production. The environmental issues can be embedded in lean manufacturing system design as shown here.

One of the biggest challenges is getting data for environmental impact analysis. The other difficulty is the accuracy or granularity of the models. It has been shown for an automobile machining line that even if the value added process (machining) is not running, the system uses a lot of energy, the maximum energy requirement for the actual machining being only $14.8 \%$ of the total. There is a significant energy requirement to start-up and maintain equipment in a "ready" position. Once ready, there follows an additional requirement proportional to the quantity of material being processed (Gutowski et al. 2006). More energy efficient equipment, i.e. variable speed drives and use of frequency converters, normally have a short payback time (Westerkamp, 2008). Simulation can help in the evaluation of equipment selection by showing the potential impacts.

To incorporate environmental considerations while analyzing manufacturing systems, a shift of focus from economic growth to only a mix of parameters is needed. Lean is a step which incorporates waste in a positive way for both economic growth and environmental friendliness due to waste reduction activities. However, in order to measure waste and emissions towards cost parameters, a discrete event simulation model can be used as a sound basis for decision support.

Johansson et al. (2008) have presented a case study in which a juice production process was modeled. The analysis incorporated both environmental effects and cost parameters. An Excel spreadsheet was used for presentation of input and output data. The SIMTER tool develops this concept one step further by actually providing an interface for environmental parameters directly in the selected simulation tool. The use of simulation component properties will also be studied, e.g. the energy and related equipment data could be stored as metadata in the component. 
In its current state, the environmental Excel workbook can be used for monitoring an existing manufacturing system, where real values from production can be entered instead of simulation results.

For future work, there are several specific challenges to be addressed with the proposed joint simulation. Such challenges include e.g. balancing manual and machine work, reducing vulnerability of manufacturing systems to disturbances while maintaining low person-hour cost, determining the influence of levels of automation on ergonomics, and environmental impacts. Also needing to be done is filling the gap between Life Cycle Assessment and conventional process simulation, and identifying the most significant environmental factors to be taken into account. The SIMTER tool will be implemented and tested in real industrial cases.

Integration with manufacturing simulation provides a structure not just for measuring performance and environmental metrics, but also for identifying where action can be taken to improve "green performance."

\section{ACKNOWLEDGEMENTS}

The authors wish to acknowledge the financial support received from the Finnish Funding Agency for Technology and Innovation (TEKES), VINNOVA (Swedish Agency for Innovation Systems), VTT, and Finnish and Swedish industry.

\section{REFERENCES}

Alexander, B., G. Barton, J. Petrie, and J. Romagnoli. 2000. Process Synthesis and Optimization Tools for Environmental Design: Methodology and Structure. Computers and Chemical Engineering 24: 1195-1200.

Alvemark, O., and F. Persson. 2007. Flow Simulation of Food Production; Cultured Dairy Products (In Swedish). M.Sc. Thesis, Department of Product and Production Development, Chalmers University of Technology, Gothenburg, Sweden.

Azapagic, A., and Clift, R. 1999. Life Cycle Assessment as a Tool for Improving Process Performance. A Case Study on Boron Products. International Journal of Life Cycle Assessment. 4(3):133-142.

EN-ISO 14040. 2006. Environmental Management. Life Cycle Assessment. Principles and Framework,

EN-ISO 14044. 2006. Environmental Management. Life Cycle Assessment. Requirements and Guidelines.

EPA. 2007a. The Lean and Environment Toolkit. U.S. Environmental Protection Agency. <http://www.epa.gov/lean/toolkit/ind ex.htm> [accessed June 26, 2008] .

EPA. 2007b The Lean and Energy Toolkit. U.S. Environmental Protection Agency, <http://www .epa.gov/lean/toolkit/Lea
nEnergyToolkit.pdf> [accessed June 26, 2008].

Facility Reporting Initiative. <http://www.facilityreporting.org > [accessed June 26, 2008].

GHG Protocol. 2008. The Greenhouse Gas Protocol Initiative. <http://www. ghgprotocol.org/> [accessed June 26, 2008].

Global Reporting Initiative.

<http://www.globalreporting.org> [accessed June 26, 2008].

GreenSCOR. 2008. <http://www.supplychain.org/> [accessed June 26, 2008]

Gutowski, T., J. Dahmus, and A. Thiriez. 2006. Electrical Energy Requirements for Manufacturing Processes. Proceedings of LCE 2006. Available at <http://www. mech.kuleuven. be/ l ce2006 / 071 .pdf $>$ [accessed June 26, 2008].

Gäbel, K., and A-M. Tillman. 2005. Simulating Operational Alternatives for Future Cement Production. Journal of Cleaner Production 13-14:1246-1257.

Harrell, C., and K. Tumay. 1995. Simulation made easy. A manager's guide. Industrial Engineering and Management Press. Institute of Industrial Engineers. ISBN 089806-136-9.

Heilala, J., O. Väätäinen, J. Montonen, T. Laaksonen, H. Kulmala. 2007. Decision Support and Simulation Methods For Assembly System Sales Engineers. In The 6th EUROSIM Congress, Ljubljana, Slovenia.

Heilala, J., K. Helin, and J. Montonen. 2006. Total cost of ownership analysis for modular final assembly systems. International Journal of Production Research 44 (18-19): 3967-3988.

Helin, K., J. Viitaniemi, S. Aromaa, J. Montonen, T. Evilä, S. Leino, and T. Määttä. 2007. OSKU Digital Human Model in the Participatory Design Approach. A New Tool to Improve Work Tasks and Workplaces. VTT Working Papers VTT-WORK-83.

Ingvarsson, A., and C. Johansson. 2006. Flow Simulation of Food Industry Production. Ingemar Johansson $i$ Sverige $A B$ (In Swedish). M.Sc. Thesis, Department of Product and Production Development, Chalmers University of Technology, Gothenburg, Sweden.

Johansson, B., J. Stahre, J. Berlin, K. Östergren, B. Sundström, and A-M Tillman. 2008. Discrete Event Simulation With Lifecycle Assessment Data At A Juice Manufacturing System. In Proceedings of FOODSIM 2008 Conference, University College Dublin, Ireland.

Jödicke, G., O. Zenklusen, A. Weidenhaupt, and K. Hungerbühler. 1999. Developing Environmentally Sound Processes in the Chemical Industry. A Case Study on Pharmaceutical Intermediates. Journal of Cleaner Production 7:159-166. 
Kheawhom, S., and M. Hirao. 2004. Decision Support Tools for Environmentally Benign Process Design under Uncertainty. Computers and Chemical Engineering 28:1715-1723.

Lind, S., B. Krassi, B. Johansson, J. Viitaniemi, J. Heilala, J. Stahre, S. Vatanen, Å. Fasth, and C. Berlin. 2008. SIMTER: A Production Simulation Tool for Joint Assessment of Ergonomics, Level of Automation and Environmental Impacts. In The 18th International Conference on Flexible Automation and Intelligent Manufacturing (FAIM 2008).

Monden, Y. 1993. Toyota Production System: An Integrated Approach to Just-in-Time. London: Chapman and Hall.

Persson, D., and J. Karlsson. 2007. Flow Simulation of Food Industry Production; Kiviks Musteri AB (In Swedish). M.Sc. Thesis, Department of Product and Production Development, Chalmers University of Technology, Gothenburg, Sweden.

Solding, P., and P. Thollander. 2006. Increased Energy Efficiency in a Swedish Iron Foundry Through Use of Discrete Event Simulation. In Proceedings of the 2006 Winter Simulation Conference, ed. L. F. Perrone, F. P. Wieland, J. Liu, B. G. Lawson, D. M. Nicol, and R. M. Fujimoto, Monterey, CA, USA.

Solding, P., and D. Petku. 2005. Applying Energy Aspects on Simulation of Energy-Intensive Production Systems, In Proceedings of the 2005 Winter Simulation Conference, ed. M. E. Kuhl, N.M. Steiger, F. B. Armstrong, and J. A. Joines, Orlando, FL, USA.

Westerkamp, T.A. 2008. It's not easy being green. IIE journal 40 (3).

Visual

Components.

<http://www.visualcomponents.com>

[accessed June 26, 2008].

\section{AUTHOR BIOGRAPHIES}

Juhani Heilala is a senior research scientist at VTT, the Technical Research Centre of Finland. He has an MSc from the Department of Mechanical Engineering at Oulu University (1989). He has 20 years' experience in production system development. His current research interest includes expanding simulation and modeling from system design and analysis methods to simulation-based manufacturing operation planning and integration of production system simulation with other analysis methods. His e-mail address is juhani.heilaladvtt.fi>.

Saija Vatanen, MSc. Tech., Energy Technology, Lappeenranta University of Technology 1998, has experience with projects on the environmental aspects of industrial products during the life cycle. She is working as a research scientist at VTT, the Technical Research Centre of Finland. Her email address is <saija.vatanenevtt.fi>.
Jari Montonen is a simulation and software development expert at VTT, the Technical Research Centre of Finland. He has 20 years' experience developing software for multiple aspects of manufacturing environments, such as machine maintenance, worker ergonomics and simulation aided planning and scheduling systems. He also has over 15 years' experience in production system simulation, having carried out dozens of simulation aided analyses of production systems for companies in many branches of industry. His e-mail address is <jari.montonen@vtt.fi>.

Hannele Tonteri, MSc. Tech., Metallurgical Engineering, Helsinki University of Technology, 1982, has long experience with projects on environmental and life cycle topics, in which she has been involved with Finnish manufacturing companies as a project manager and researcher. She is working as a senior research scientist at VTT, the Technical Research Centre of Finland. Her email address is $<$ hannele.tonterievtt.fi>.

Björn Johansson is an assistant professor at Product and Production Development, Chalmers University of Technology. His research interest lies in the area of discrete event simulation for manufacturing industries. He is interested in the specifics of modular modeling methodology for effective and swift model-building, which is accompanied by software development, user interfaces, and input data architectures. His email address is <bjorn.johansson@chalmers.se>.

Johan Stahre is a professor at Product and Production Development, Chalmers University of Technology. His department's research and educational efforts focus on the areas of robust production, production ergonomics, production simulation, and assembly systems. Johan Stahre's personal research interests center on automation, human supervisory control, and human/system interaction in manufacturing contexts. His email address is $<j \circ-$ han.stahre@chalmers.se>.

Salla Lind M.Sc, is a research scientist at VTT. She received her Master's degree from Tampere University of Technology in 2001. Currently Ms. Lind is finalizing her $\mathrm{Ph} . \mathrm{D}$. thesis on safety risk management in industrial maintenance. Her scientific interests include safety and human factors in industrial workplaces. She is the project manager of the SIMTER project. Her email address is <salla.lindevtt.fi>. 